\title{
Reação de Resistência Tipo I e Tipo II a Giberela em cultivares de trigo
}

\author{
Rafael Hansen Alves ${ }^{1}$, Tatiane Dalla Nora ${ }^{2}$, Francisco de Assis Franco ${ }^{2}$, Antonio Carlos Torres da Costa ${ }^{1}$ e José \\ Renato Stangarlin ${ }^{1}$
}

${ }^{1}$ Universidade Estadual do Oeste do Paraná, Campus de Marechal Cândido Rondon, Centro de Ciências Agrárias, Cx. Postal 91, 85960-000, Marechal Cândido Rondon-PR; ${ }^{2}$ Cooperativa Central de Pesquisa Agrícola, Cx. Postal 301, 85813-450, Cascavel-PR.

Autor para correspondência: Antonio Carlos Torres da Costa (antonio.costa2@unioeste.br)

Data de chegada: 30/01/2013. Aceito para publicação em: 19/07/2013.

1867

\section{RESUMO}

Alves, R.H.; Nora, T.D.; Franco, F.A.; Costa, A.C.T.; Stangarlin, J.R. Reação de Resistência Tipo I e Tipo II a Giberela em cultivares de trigo. Summa Phytopathologica, v.39, n.3, p.167-171, 2013.

O objetivo deste trabalho foi avaliar as reações de resistência tipo I e tipo II à giberela em 28 cultivares de trigo em casa de vegetação. A inoculação de Fusarium graminearum foi realizada no estádio de florescimento. Para a resistência tipo I, a avaliação foi feita 21 dias após a inoculação. Foi determinada a severidade no estádio de espiga seca e a porcentagem de grãos giberelados. A avaliação da severidade foi feita pela porcentagem de espiguetas infectadas, no estádio de espiga verde atribuindo-se uma nota em uma escala linear de zero (nenhuma infecção) a 100 (100\% de espiguetas infectadas). Para a resistência tipo II, as avaliações foram realizadas aos 7, 14 e 21 dias após a inoculação, contando-se as espiguetas com sintomas da doença, excluindo as duas espiguetas que foram inoculadas. As cultivares Frontana, BRS 177, BRS 179, BRS Umbu, BRS Camboim, Abalone, Ônix, Pampeano e Fundacep 30 apresentaram menor severidade da doença e menor porcentagem de grãos giberelados, demonstrando serem fontes de resistência tipo I. As cultivares BRS Guamirim, CD 120, Onix, Rubi, Fundacep 50, BRS 179, Pampeano, Abalone, CD 114, IPR 85, Safira, BRS Louro, CD 117, CDF 2002116, CD 115, BRS 177, CD 0529 e BRS Camboim apresentaram a menor área abaixo da curva de progresso da doença, demonstrando a presença da resistência do tipo II.

Palavras-chave adicionais: Triticum aestivum, Fusarium graminearum, Giberella zeae.

\section{ABSTRACT}

Alves, R.H.; Nora, T.D.; Franco, F.A.; Costa, A.C.T.; Stangarlin, J.R. Type I and type II resistance reaction to FHB in wheat cultivars. Summa Phytopathologica, v.39, n.3, p.167-171, 2013.

The aim of this study was to evaluate type I and type II resistance reactions to FHB for 28 wheat cultivars grown in a greenhouse. The inoculation of Fusarium graminearum was performed in the flowering stage. For type I resistance, the assessment was made at 21 days after inoculation. The disease severity was determined in the dry ear stage, as well as the percentage of scabby grains. The evaluation of disease severity was performed by using the percentage of infected spikelets in the green ear stage, assigning a score on a linear scale from zero (no infection) to 100 (100\% infected spikelets). For type II resistance, assessments were performed at 7,14 and 21 days after inoculation by counting the spikelets with symptoms, excluding the two inoculated spikelets. The cultivars Frontana, BRS 177, BRS 179, BRS Umbu, BRS Camboim, Abalone, Onyx, Pampeano and Fundacep 30 showed less disease severity and lower percentage of scabby grains, demonstrating thus potential to be sources of type I resistance. The cultivars BRS Guamirim, CD 120, Onyx, Ruby, Fundacep 50, BRS 179, Pampeano, Abalone, CD 114, IPR 85, Safira, BRS Louro, CD 117,CDF 2002116, CD 115, BRS 177, CD 0529 and BRS Camboim showed the smallest area under the disease progress curve, demonstrating thus type II resistance.

Additional keywords: Triticum aestivum, Fusarium graminearum, Giberella zeae.

A giberela em trigo é causada por Fusarium graminearum Schwabe (Giberella zeae (Schw.) Petch.), fungo que além de causar redução no rendimento da cultura pode ser responsável pela presença de micotoxinas nos grãos e derivados (15). Os mecanismos de resistência para o gênero Fusarium em trigo são classificados em morfológicos ou fisiológicos, sendo ambos mecanismos, governados por expressão genética (20).

Algumas características morfológicas estão associadas com o aumento da doença. Em genótipos com aristas, pedúnculo curto e espiga compacta, a tendência é de rápida disseminação do patógeno, ao contrário de genótipos sem aristas, com pedúnculo longo e espiga laxa. Além disso, os genótipos de porte baixo são mais severamente infectados do que os genótipos de porte alto. A resistência fisiológica envolve, consequentemente, rotas bioquímicas com a produção de compostos que inibem o patógeno após a infecção (17). Os mecanismos bioquímicos e moleculares da resistência à giberela do trigo ainda são desconhecidos. Diversos padrões de expressão da defesa estão relacionados com proteínas e enzimas. Assim, ácido ascórbico, peroxidase e catalase foram observadas entre linhagens de trigo resistentes e suscetíveis (1).

Mesterhazy (17) descreveu cinco mecanismos de resistência à giberela. Estão incluídos: tipo I: resistência à infecção inicial; tipo II: 
resistência à propagação no interior da espiga; tipo III: redução do acúmulo de desoxinivalenol (DON) não correlacionado com as resistências do tipo I e II; tipo IV: resistência dos grãos à infecção (mesmo que a espiga esteja infectada); tipo V: tolerância (menor perda de produtividade, mesmo com elevada infecção).

Segundo Bai \& Shaner (2) os tipos de resistência I e II são os mais estudados, e várias metodologias têm sido desenvolvidas para avaliar e distinguir esses tipos de resistência pelos melhoristas de plantas.

De acordo com Lima \& Fernandes (14), apresentam resistência a giberela alguns genótipos desenvolvidos no Sul do Brasil, todavia, desconhece-se o tipo de resistência presente individualmente nestas cultivares.

No entendimento de Mesterhazy (16), os mecanismos de resistência ativos (fisiológicos) incluem a inibição da infecção, restrição de colonização após a infecção, e a degradação metabólica de substâncias produzidas pelo patógeno. Os esforços de melhoramento em todo o mundo estão concentrados principalmente na resistência do tipo II. Os estudos têm indicado que sob condições de epidemia a resistência tipo I é facilmente ultrapassada, e que, a resistência do tipo II é a mais promissora para reduzir as perdas devido à infecção por Fusarium graminearum.

O objetivo deste trabalho foi avaliar as reações de resistência tipo I e tipo II à giberela em 28 cultivares de trigo cultivados em casa-devegetação.

\section{MATERIAL E MÉTODOS}

O trabalho foi desenvolvido em casa de vegetação na COODETEC - Cooperativa Central de Pesquisa Agrícola, sediada em Cascavel-PR. Foram utilizadas as cultivares: Abalone, BRS Timbaúva, BRS Camboim, BRS Umbu, BRS 208, BRS 179, BRS 177, BRS Louro, BRS Guamirim, CD 105, CD 114, CD 115, CD 116, CD 117, CD 0529, CD 120, CDF 2002116, IPR 85, Frontana, Fundacep Nova Era, Fundacep Raízes, Fundacep 30, Fundacep 50, Fundacep 52, Ônix, Pampeano, Rubi e Safira.

Utilizou-se o delineamento experimental inteiramente casualizado, com 28 tratamentos (cultivares) e quatro repetições para avaliar a resistência tipo I, e cinco repetições para a resistência tipo II. Os experimentos foram conduzidos em vasos de $5 \mathrm{~L}$, contendo uma mistura de terra, areia e matéria orgânica na proporção de 2:1:1.

\section{Resistência Tipo I}

A inoculação do patógeno foi realizada no florescimento nos estádios 10.5.2 e 10.5.3, segundo a escala de Large (12), pela aspersão de suspensão de conídios do fungo na espiga, usando um borrifador manual até o ponto de escorrimento. Em seguida, as plantas foram mantidas em saco plástico para proporcionar umidade elevada ao redor da espiga, por $48 \mathrm{~h}$, em temperatura de $24{ }^{\circ} \mathrm{C}$.

A obtenção de esporos foi realizada através da raspagem de placas de Petri com meio batata-dextrose-ágar (BDA) colonizadas por Fusarium graminearum. Os conídios foram removidos com água destilada e com auxílio de pincel. A concentração foi ajustada para $5 \times 10^{4}$ esporos $/ \mathrm{mL}$. A contagem foi realizada em microscópio óptico em Câmara de Neubauer. Quando 50\% das plantas atingiram a antese, a pulverização foi realizada com a suspensão de esporos.

A avaliação foi realizada 21 dias após a inoculação. Foi determinada a severidade da doença no estádio de espiga seca e a porcentagem de grãos giberelados. A avaliação da severidade da doença foi através da porcentagem de espiguetas infectadas, no estádio de espiga verde, atribuindo-se uma nota por escala linear de zero (nenhuma infecção) a 100 (100\% de espiguetas infectadas), conforme sugerido por Stack \& McMullen (23).

\section{Resistência Tipo II}

À medida que as plantas atingiram a antese, as espigas selecionadas (preferencialmente em antese) foram inoculadas. A obtenção, a concentração e a contagem de esporos foram feitas conforme descrito no item anterior.

Aproximadamente $10 \mathrm{~mL}$ da suspensão de esporos (macroconídios) na concentração de $5 \times 10^{4}$ esporos $/ \mathrm{mL}$ foi injetada entre a lema e a pálea de uma espigueta, nos dois lados da espiga, utilizando uma seringa com agulha hipodérmica. O ponto de infecção em cada espiga foi o par de espiguetas centrais, sendo inoculada uma de cada lado da espiga.

Após a inoculação, foi aspergida água com auxílio de um borrifador manual e utilizado um saco plástico para proporcionar umidade elevada ao redor da espiga, o qual foi mantido por $48 \mathrm{~h}(3,8,25)$.

As avaliações foram realizadas aos 7; 14 e 21 dias após a inoculação, contando-se as espiguetas com sintomas da doença, excluindo as duas que foram inoculadas. $\mathrm{O}$ número total de espiguetas de cada espiga também foi contado no $21^{\circ}$ dia, para transformar a incidência de espiguetas doentes em porcentagem.

A análise estatística foi realizada com os softwares estatísticos SASM-Agri (6) e SISVAR (10). Os dados obtidos foram submetidos à análise de variância (ANAVA). As médias foram comparadas pelo teste Scott-Knott a $5 \%$ de probabilidade. Para a análise dos dados do número de espiguetas com sintomas da doença e severidade da doença em espiga foi utilizada a transformação arco seno $\sqrt{\mathrm{X} / 100(11)}$.

\section{RESULTADOS E DISCUSSÃO}

\section{Resistência Tipo I}

Houve diferença significativa entre as cultivares (Tabela 1). As cultivares CD 115, Fundacep 50, Safira, Fundacep Nova Era, CD 114, CD 0529, Fundacep 52, CDF 2002116 e Rubi apresentaram maior média de severidade de giberela. Por outro lado, as cultivares BRS Camboim, CD 116, Frontana, IPR 85, Pampeano, CD 105, BRS 208, CD 117, BRS Louro, BRS Umbú, BRS Timbaúva, BRS 179, Fundacep 30, Onix, CD 120, Fundacep Raízes, Abalone, BRS Guamirim e BRS 177 apresentaram menor severidade.

Em trabalho conduzido a campo por Casa et al. (7), que avaliaram a severidade de giberela no estádio de espiga seca, foi observado que as cultivares BRS 177 e BRS 179 apresentaram médias de severidade da doença na espiga semelhantes as deste trabalho, no grupo de menor intensidade da doença.

Em relação aos grãos com sintomas de giberela, também houve diferença significativa entre as cultivares (Tabela 1). Foi possível separar os materiais testados em três grupos, grupo I: IPR 85, BRS 208 e CD 116; grupo II: BRS Guamirim, CD 120, CD 105, CD 114, Fundacep Raízes, Fundacep Nova Era, CD 117, BRS Louro e BRS Timbaúva; e grupo III: as demais cultivares.

Em estudo para a identificação de fontes de resistência a giberela, Rivadeneira (19) verificou que as cultivares BRS 179 e BRS 177 apresentaram a menor porcentagem de grãos giberelados, sendo que no presente trabalho estas cultivares apresentaram resultados semelhantes, estando presentes no grupo de menor porcentagem de grãos giberelados. Lima et al. (15) identificaram menor porcentagem de grãos giberelados nestas cultivares, além de Pampeano, Safira, Onix, 
Tabela 1. Severidade (\%) no estádio "espiga seca" e grãos com sintomas de giberela $(\% \mathrm{GG})$ em cultivares de trigo em casa de vegetação

\begin{tabular}{|c|c|c|}
\hline Cultivares & Severidade & Grãos Giberelados (\%) \\
\hline Pampeano & $0,9199 \mathrm{~b}$ & $0,2716 \mathrm{c}$ \\
\hline Safira & 1,3492 a & $0,2990 \mathrm{c}$ \\
\hline Onix & $0,7938 \mathrm{~b}$ & $0,4542 \mathrm{c}$ \\
\hline Rubi & $1,1114 \mathrm{a}$ & $0,3945 \mathrm{c}$ \\
\hline Abalone & $0,6925 \mathrm{~b}$ & $0,4558 \mathrm{c}$ \\
\hline BRS Timbaúva & $0,8319 \mathrm{~b}$ & $0,4833 \mathrm{~b}$ \\
\hline BRS Camboim & $1,0134 \mathrm{~b}$ & $0,3177 \mathrm{c}$ \\
\hline BRS Umbú & $0,8437 \mathrm{~b}$ & $0,3211 \mathrm{c}$ \\
\hline BRS 208 & $0,8795 \mathrm{~b}$ & $0,8322 \mathrm{a}$ \\
\hline BRS 179 & $0,8077 \mathrm{~b}$ & $0,3014 \mathrm{c}$ \\
\hline BRS 177 & $0,6422 \mathrm{~b}$ & $0,2271 \mathrm{c}$ \\
\hline BRS Louro & $0,8621 \mathrm{~b}$ & $0,4966 \mathrm{~b}$ \\
\hline BRS Guamirim & $0,6795 \mathrm{~b}$ & $0,6588 \mathrm{~b}$ \\
\hline IPR 85 & $0,9431 \mathrm{~b}$ & $0,8510 \mathrm{a}$ \\
\hline Fundacep Nova era & $1,3049 \mathrm{a}$ & $0,5272 \mathrm{~b}$ \\
\hline Fundacep Raízes & $0,7426 \mathrm{~b}$ & $0,5708 \mathrm{~b}$ \\
\hline Fundacep 30 & $0,8013 \mathrm{~b}$ & $0,3039 \mathrm{c}$ \\
\hline Fundacep 50 & 1,4428 a & $0,2410 \mathrm{c}$ \\
\hline Fundacep 52 & 1,1249 a & $0,3628 \mathrm{c}$ \\
\hline CD105 & $0,9034 \mathrm{~b}$ & $0,6147 \mathrm{~b}$ \\
\hline CD114 & $1,1789 \mathrm{a}$ & $0,5718 \mathrm{~b}$ \\
\hline CD 115 & $1,3637 \mathrm{a}$ & $0,3389 \mathrm{c}$ \\
\hline CD 116 & $1,0113 \mathrm{~b}$ & $0,7415 \mathrm{a}$ \\
\hline CD 117 & $0,8622 \mathrm{~b}$ & $0,5120 \mathrm{~b}$ \\
\hline CD 0529 & $1,1359 \mathrm{a}$ & $0,4012 \mathrm{c}$ \\
\hline CD 120 & $0,7699 \mathrm{~b}$ & $0,6460 \mathrm{~b}$ \\
\hline CDF 2002116 & $1,1148 \mathrm{a}$ & $0,2273 \mathrm{c}$ \\
\hline Frontana & $0,9817 \mathrm{~b}$ & $0,3426 \mathrm{c}$ \\
\hline CV (\%) & 26,86 & 36,20 \\
\hline
\end{tabular}

Dados transformados em arco seno $\sqrt{ } \mathrm{X} / 100$. Médias seguidas da mesma letra minúscula na coluna, não diferem estatisticamente entre si pelo teste Scott-Knott, a 5\% de probabilidade.

Rubi, BRS Timbaúva e BRS Umbu; resultados próximos foram obtidos neste trabalho.

Miller \& Arniston (18), Mesterhazy (16) e Ban (5) relataram que a cultivar Frontana é caracterizada como resistente. Neste trabalho, foi possível verificar que esta cultivar esteve presente no grupo de menor porcentagem de grãos giberelados (Tabela 1).

\section{Resistência Tipo II}

A giberela ocorreu de forma intensa neste ensaio em casa de vegetação, provavelmente por se tratar de um ambiente controlado e pelo método de inoculação e incubação.

A análise de variância para os valores de incidência mostrou diferenças significativas entre as cultivares. Aos 7 dias após a inoculação (DAI), as cultivares foram divididas em quatro grupos; aos $14 \mathrm{DAI}$ as cultivares formaram dois grupos, e aos 21 dias DAI as cultivares foram agrupadas em três grupos (Tabela 2).

Aos 7 DAI, a incidência de espiguetas infectadas foi baixa, como já era esperado. Todavia, materiais como Frontana, CD 116, Fundacep 52, Fundacep Raízes e Fundacep Nova Era (grupo de maior incidência)
Tabela 2. Incidência (\%) da giberela em espiguetas de trigo aos 7;14 e 21 dias após a inoculação (DAI), em casa de vegetação

\begin{tabular}{|c|c|c|c|}
\hline Cultivares & 7 DAI & 14 DAI & 21 DAI \\
\hline Pampeano & $2,36 \mathrm{~d}$ & $26,09 \mathrm{~b}$ & $54,30 \mathrm{c}$ \\
\hline Safira & $6,98 \mathrm{c}$ & $25,42 \mathrm{~b}$ & $56,59 \mathrm{~b}$ \\
\hline Onix & $6,47 \mathrm{c}$ & $17,45 \mathrm{~b}$ & $43,71 \mathrm{c}$ \\
\hline Rubi & $9,56 \mathrm{c}$ & $21,00 \mathrm{~b}$ & $46,99 \mathrm{c}$ \\
\hline Abalone & $13,15 \mathrm{~b}$ & $23,56 \mathrm{~b}$ & $50,23 \mathrm{c}$ \\
\hline BRS Timbaúva & $12,03 \mathrm{~b}$ & $31,08 \mathrm{a}$ & $60,05 \mathrm{~b}$ \\
\hline BRS Camboim & $13,29 \mathrm{~b}$ & $27,03 \mathrm{~b}$ & $62,00 \mathrm{~b}$ \\
\hline BRS Umbú & $11,44 \mathrm{~b}$ & $32,18 \mathrm{a}$ & $75,52 \mathrm{a}$ \\
\hline BRS 208 & $14,01 \mathrm{~b}$ & 35,49 a & $66,81 \mathrm{a}$ \\
\hline BRS 179 & $10,40 \mathrm{c}$ & $22,65 \mathrm{~b}$ & $52,97 \mathrm{c}$ \\
\hline BRS 177 & $14,48 \mathrm{~b}$ & $26,35 \mathrm{~b}$ & $55,83 \mathrm{~b}$ \\
\hline BRS Louro & $12,70 \mathrm{~b}$ & $24,28 \mathrm{~b}$ & $54,47 \mathrm{c}$ \\
\hline BRS Guamirim & $6,80 \mathrm{c}$ & $16,21 \mathrm{~b}$ & $30,29 \mathrm{c}$ \\
\hline IPR 85 & $12,82 \mathrm{~b}$ & $24,49 \mathrm{~b}$ & $51,38 \mathrm{c}$ \\
\hline Fundacep Nova Era & 19,52 a & 34,77 a & $71,80 \mathrm{a}$ \\
\hline Fundacep Raízes & $20,39 \mathrm{a}$ & 39,72 a & 70,89 a \\
\hline Fundacep 30 & $16,06 \mathrm{~b}$ & 30,93 a & $60,29 \mathrm{~b}$ \\
\hline Fundacep 50 & $13,21 \mathrm{~b}$ & $24,35 \mathrm{~b}$ & $45,89 \mathrm{c}$ \\
\hline Fundacep 52 & $21,05 \mathrm{a}$ & $40,01 \mathrm{a}$ & $61,15 \mathrm{~b}$ \\
\hline CD 105 & $16,10 \mathrm{~b}$ & $31,72 \mathrm{a}$ & $59,06 \mathrm{~b}$ \\
\hline CD 114 & $13,46 \mathrm{~b}$ & $26,59 \mathrm{~b}$ & $46,21 \mathrm{c}$ \\
\hline CD 115 & $15,30 \mathrm{~b}$ & 29,66 a & $47,85 \mathrm{c}$ \\
\hline CD 116 & $21,27 \mathrm{a}$ & $36,53 \mathrm{a}$ & $57,53 \mathrm{~b}$ \\
\hline CD 117 & $14,48 \mathrm{~b}$ & $26,35 \mathrm{~b}$ & $55,83 \mathrm{~b}$ \\
\hline CD 0529 & $16,97 \mathrm{~b}$ & 30,58 a & $45,94 \mathrm{c}$ \\
\hline CD 120 & $10,15 \mathrm{c}$ & $20,07 \mathrm{~b}$ & $34,30 \mathrm{c}$ \\
\hline CDF 2002116 & $15,68 \mathrm{~b}$ & $28,41 \mathrm{~b}$ & $49,53 \mathrm{c}$ \\
\hline Frontana & $23,65 \mathrm{a}$ & $39,01 \mathrm{a}$ & $72,70 \mathrm{a}$ \\
\hline CV (\%) & 19,82 & 16,29 & 13,84 \\
\hline
\end{tabular}

Médias seguidas de mesma letra, não diferem estatisticamente entre si pelo teste Scott-Knott a 5\% de probabilidade.

apresentaram nesta etapa de avaliação maior percentual de espiguetas infectadas, enquanto os materiais BRS 179, CD 120, Rubi, Safira, BRS Guamirim e Onix, apresentaram baixa incidência de giberela. A cultivar Pampeano, foi a única cultivar incluída no grupo de menor intensidade da doença aos 7 DAI, com apenas $2 \%$ de incidência. É importante ressaltar que em casa-de-vegetação, sintomas de giberela normalmente aparecem nas espiguetas três dias após a inoculação (3).

Aos 14 DAI, já foi possível observar incremento na intensidade da doença. $\mathrm{O}$ grupo de maior incidência aumentou, pois além das cultivares citadas anteriormente, foram incluídas: BRS 208, BRS Umbú, CD 105, BRS Timbaúva, CD 0529, Fundacep 30 e CD 115. As demais cultivares foram incluídas no grupo de menor severidade nesta etapa de avaliação.

A última avaliação foi realizada aos $21 \mathrm{DAI}$, com incidência elevada de giberela. O grupo com maior incidência foi reduzido, quando comparado aos 14 DAI, sendo eles: BRS Umbú, Frontana, Fundacep Nova Era, Fundacep Raízes e BRS 208.

O grupo de incidência intermediária aos $21 \mathrm{DAI}$ incluiu cultivares que estiveram presentes nos grupos de maior intensidade da doença 
nas duas primeiras avaliações, como: Fundacep 52, Fundacep 30, BRS Timbaúva, CD 105 e CD 116; bem como, também, as cultivares Safira e BRS 177, que aos 7 e 14 DAI apresentaram menor intensidade da doença.

Dentre o grupo de menor incidência aos $21 \mathrm{DAI}$, apenas a cultivar CD 115 esteve incluída no grupo de maior intensidade da doença aos 14 DAI. As demais cultivares presentes neste grupo, ou estiveram em grupos intermediários ou nos grupos de menor incidência média nas avaliações anteriores (Tabela 2).

A cultivar Frontana é relatada na literatura como fonte de resistência a giberela, sendo frequentemente utilizada como um dos progenitores em programas de melhoramento de trigo $(5,17)$. Neste experimento, Frontana não demonstrou resistência à colonização do fungo através da espiga. No entanto, Singh et al. (21) relatam que há uma baixa incidência da doença na cultivar Frontana no campo. O resultado encontrado pode ser explicado por ser frequente na cultivar Frontana a resistência do tipo I, aquela caracterizada pela resistência da planta à infecção inicial, sendo este tipo de resistência mais facilmente observada em experimentos conduzidos em condições de campo (13).

Outro aspecto relevante se deve ao ciclo desse material. Segundo Sousa (22), Frontana é caracterizada por ser de ciclo precoce, portanto, seu espigamento/florescimento ocorre num período inferior a 80 dias. Todavia, o comportamento desta cultivar neste experimento, em ambiente controlado, mostrou que Frontana foi a última cultivar a entrar em espigamento, embora, deva-se ressaltar que a inoculação de todas as cultivares ocorreu durante a antese.

A cultivar BRS Umbú que também está no grupo de maior incidência média da doença aos 21 DAI, é caracterizada por ser de ciclo tardio (9). Embora este experimento tenha sido realizado em ambiente controlado, é provável que a quantidade de inóculo no ambiente pudesse ter aumentado gradualmente, permitindo que cultivares com ciclos mais longos estivessem mais expostas a doenças.

É possível observar o progresso da giberela pela análise da área abaixo da curva de progresso da doença (AACPD) na Figura 1. A cultivar BRS Guamirim tem ciclo precoce com espigamento médio de 78 dias e BRS 179 tem ciclo médio, 89 dias (9). As demais cultivares do grupo de menor incidência também possuem ciclos precoces ou médios. A cultivar BRS Guamirim foi o primeiro material a entrar no estádio de espigamento/florescimento, assim como as demais cultivares desse grupo que obtiveram comportamento semelhante. De certa forma, mesmo com condições controladas de ambiente e de inoculação, existe uma pressão de inóculo atuando. Provavelmente, as cultivares desse grupo anteciparam-se ao período crítico de maior intensidade e pressão do inóculo e, dessa forma, apresentaram uma curva de progresso da doença inferior ao grupo mais suscetível (Figura 1).

Quando se trata de resistência genética à giberela, os genótipos de trigo asiáticos são os mais bem estudados, com destaque para a variedade chinesa Sumai $3(4,24)$. A cultivar Pampeano utilizada nesse experimento possui em sua genealogia o material chinês Sumai 3. Van Ginkel et al. (24), utilizando uma população de Ning 7840, derivada de Sumai 3, identificaram dois genes dominantes para a resistência do tipo II. Portanto, é provável que a cultivar Pampeano possua em seu genótipo genes para resistência do tipo II a giberela. Logo, os resultados obtidos neste experimento estão de acordo com os relatos da literatura, visto que esta cultivar esteve sempre no grupo de maior resistência nas três avaliações realizadas. As cultivares Onix, Rubi, Abalone, BRS 179, BRS Louro, BRS Guamirim, Fundacep 50, CD 114, CD 120 e CDF 2002116, que estão presentes no mesmo grupo, uma vez que, são estatisticamente iguais, podem possuir um mecanismo similar que possibilitou apresentar baixa intensidade da doença em condições de inoculação nas espiguetas.

Aos 21 DAI, foi possível constatar que dentre as cultivares

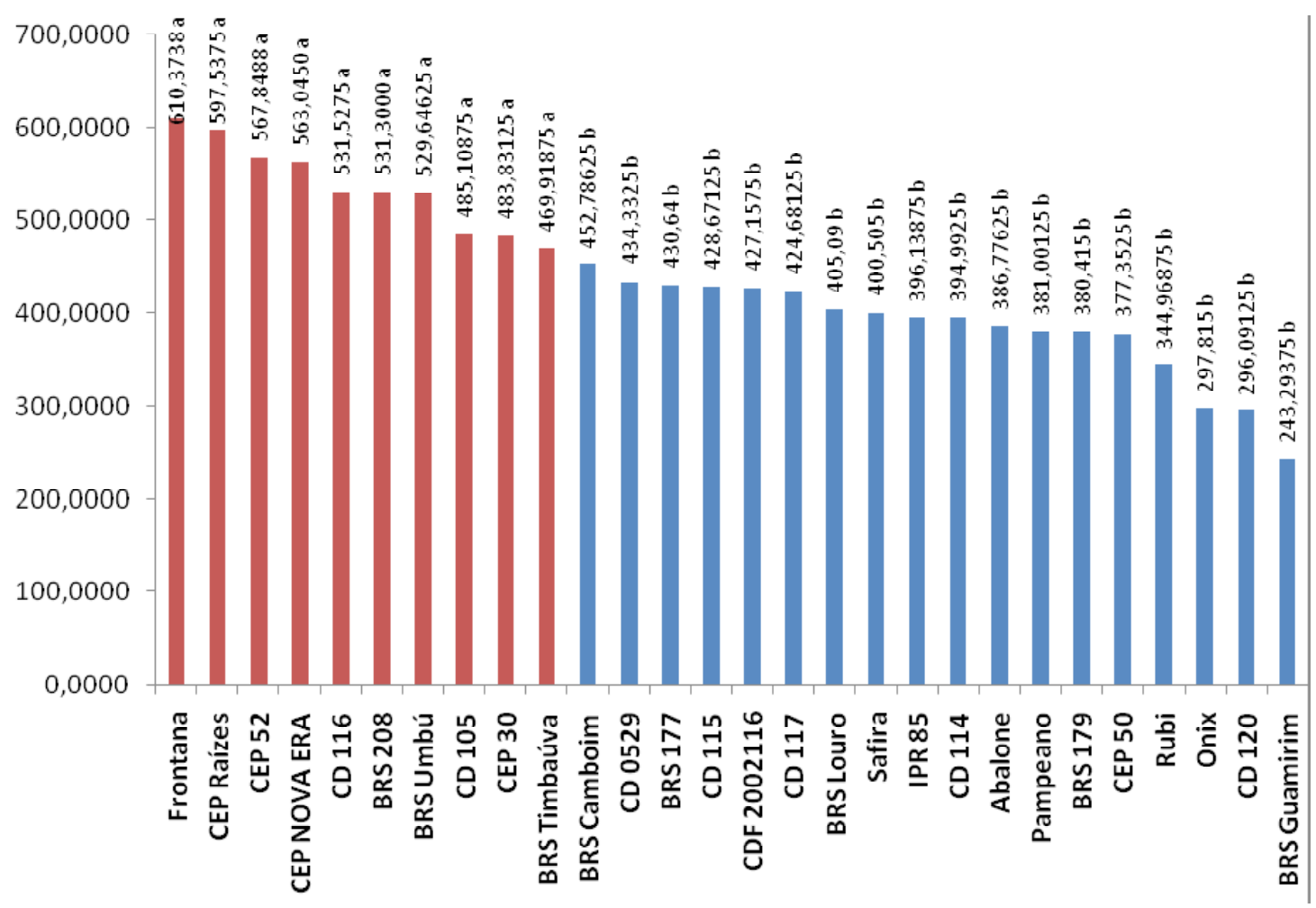

Figura 1. Área abaixo da curva de progresso da giberela (AACPD) em espiguetas de trigo inoculadas em casa de vegetação 
incluídas no grupo de maior severidade, duas possuem reação de resistência a giberela, sendo elas, BRS Umbú e Frontana (Tabela 2). No entanto, observando os resultados apresentados, existe indício da presença apenas da resistência do tipo I nesses genótipos, devido à incapacidade destes materiais em retardar o avanço da propagação da doença através da espiga. No grupo intermediário, enquadraram-se somente BRS Camboim, BRS Timbaúva e BRS 177, que fenotipicamente não mostraram um padrão elevado de resistência do tipo II (Tabela 2). No grupo de menor incidência aos 21 DAI, apenas BRS Louro, Pampeano e BRS 179 têm descrição de moderada resistência à giberela. As demais cultivares foram classificadas como moderadamente suscetíveis à doença, sendo que esses materiais apresentaram as menores médias de incidência dentro desse grupo, similares aos resultados obtidos pelas cultivares caracterizadas como de melhor resistência (Tabela 2).

É relevante ressaltar que dentre os genótipos testados nesse experimento, apenas Frontana já foi submetido a estudo anterior em casa de vegetação para resistência do tipo II. Para todos os outros não existem relatados na literatura de presença ou ausência deste tipo específico de resistência. Partindo-se desta premissa, é possível interpretar os resultados obtidos por essas cultivares como uma resposta ao método de inoculação e ao ambiente proporcionado. Como a inoculação foi pontual, e não houve vários pontos de inoculação simultâneos, ausência de variação climática e ambiental, como ocorre em condições de campo, a planta provavelmente conseguiu ativar seu mecanismo de defesa impedindo o progresso do patógeno através da espiga. No entanto, estudos posteriores são necessários para confirmação da natureza dessa reação, seja ela genética ou fisiológica. Estas informações seriam importantes para o melhoramento de trigo.

Os resultados obtidos neste trabalho permitem concluir que as cultivares Frontana, BRS 177, BRS 179, BRS Umbu, BRS Camboim, Abalone, Ônix, Pampeano e Fundacep 30 apresentaram menor severidade da doença e menor porcentagem de grãos giberelados, demonstrando assim que podem ser utilizados como fontes de resistência tipo I à giberela.

As cultivares BRS Guamirim, CD 120, Onix, Rubi, Fundacep 50, BRS 179, Pampeano, Abalone, CD 114, IPR 85, Safira, BRS Louro, CD 117, CDF 2002116, CD 115, BRS 177, CD 0529 e BRS Camboim apresentaram a menor área abaixo da curva de progresso da doença (AACPD), demonstrando potencial para a resistência do tipo II a giberela.

\section{REFERÊNCIAS BIBLIOGRÁFICAS}

1. Bai, G.; Shaner, G. Management and resistance in wheat and barley to Fusarium Head Blight. Annual Review of Phytopathology, Palo Alto, v.42, p.135-161, 2004.

2. Bai, G.H; Shaner, G. Scab of wheat: prospects for control. Plant Disease, St.Paul, v.78, p.760-765, 1994.

3. Bai, G.H; Shaner, G. Variation in Fusarium graminearum and cultivar resistance to wheat scab. Plant Disease, St. Paul, v.80, p.975-979, 1996.

4. Bai, G.H; Shaner, G.; Ohm, H. Inheritance of resistance to Fusarium graminearum in wheat. Theorical and Applied Genetics, Heidelberg, v.100, p.1-8, 2000.

5. Ban, T. Studies on the genetics of resistance to Fusarium head blight caused by $F$. graminearum Schwabe in wheat (Triticum aestivum L.). Bulletin of the Kyushu National Agricultural Experiment Station, Kyushu, v.38, p.27-78, 2001.

6. Canteri M.G.; Althaus R.A.; Virgens Filho J.S.; Giglioti E.A.; Godoy C.V. SASM - Agri: Sistema para análise e separação de médias em experimentos agrícolas pelos métodos Scott - Knott, Tukey e Duncan. Revista Brasileira de Agrocomputação, Ponta Grossa, v.1, p.18-24, 2001.

7. Casa, R.T.; Bogo, A.; Moreira, E.N.; Kuhnem J.R.P.R. Época de aplicação e desempenho de fungicidas no controle da giberela em trigo. Ciência Rural, Santa Maria, v.37, p.1558-1563, 2007.

8. Cuthbert P.A.; Somers, D.J.; Thomas, J.; Cloutier, S.; Brulé-Babel, A. Fine mapping FHB1, a major gene controlling fusarium head blight resistance in wheat (Triticum aestivum L.). Theoretical and Applied Genetics, Heidelberg, v.112, p.1465-1472, 2006.

9. EMBRAPA. Informações técnicas de cultivares de trigo. Passo Fundo/RS, 2010. Disponível em: <http:// www.cnpt.embrapa.br/culturas/trigo/cultivares/index.htm>. Acesso em: 20 abr. 2010.

10. Ferreira, D.F. Análise estatística por meio do SISVAR (Sistema para Análise de Variância) para Windows versão 4.0. In: Reunião Anual da Região Brasileira da Sociedade Internacional de Biometria, 45., 2000, São Carlos. Anais. São Carlos: UFSCar, 2000.p.255-258.

11. Gomes, F.A.P. Estatística moderna na pesquisa agropecuária. Piracicaba: Potafos, 1984. 160p.

12. Large, E.C. Growth stage in cereals: illustration of the Feekes scale. Plant Pathology, Oxford, v.3, p.128-129, 1954

13. Lima, M.I.P.M. Determinação da resistência de cultivares de trigo à giberela. Fitopatologia Brasileira, Brasília, v.29, supl., p.119, 2004. (Resumo).

14. Lima, M.I.P.M.; Fernandes, J.M.C. Avaliação da resistência à giberela em trigo. Fitopatologia Brasileira, Brasília, v.25, p. 30-35, 2000.

15. Lima, M.I.P.M.; Silva, M.; Scheeren, P.L.; Del Duca, L. De J.A.; Pires, J.L.; Nascimento Junior, A. do. Avaliação de giberela em genótipos de trigo do ensaio estadual de cultivares, na região de Passo Fundo, em 2004. Passo Fundo: Embrapa Trigo, 2005. 11 p. (Documentos, 52).

16. Mesterhazy, A. Breeding for resistance to Fusarium head blight of wheat. In:. Dubin, H.J.; Gilchrist, L.; Reeves, J.; Mcnab, A. (Eds.). Fusarium Head Bligth. México: CIMMYT, 1997. p.7985.

17. Mesterhazy, A. Types and components of resistance to Fusarium head blight of wheat. Plant Breeding, Berlin, v.114, p.377386,1995 .

18. Miller, J.D.; Arniston, P.G. Degradation of deoxynivalenol by suspension cultures of fusarium head blight resistant wheat cultivar Frontana. Canadian Journal of Plant Pathology, Ontario, v.8, p.147-150, 1986 .

19. Rivadeneira, M. Variabilidade de Fusarium spp. agente etiológico de giberela em trigo e identificação de fontes de resistência à fusariose da espiga em trigos sintéticos. 2001. 71f. Dissertação (Mestrado) - Universidade de Passo Fundo, Passo Fundo.

20. Rudd, J.C.; Horsley, R.D.; Mckendry, A.L.; Elias, E.M. Host plant resistance genes for Fusarium head blight: I. Sources mechanisms and utility in conventional breeding systems. Crop Science, Madison, v.41, p.620-627, 2001.

21. Singh, R.P.; Ma, H.; Rajaram, S. Genetic analysis of resistance to scab in spring wheat Frontana. Plant Disease. St. Paul, v.79, p.238-240, 1995.

22. Sousa, C.N.A. Contribuição das cultivares de trigo de Strampelli para o melhoramento de trigo no Brasil. Passo Fundo: Embrapa Trigo, 2001. 5p. (Documentos, 7).

23. Stack, R.W.; Mcmullen, M.P. A visual scale to estimate severity of fusarium head blight in wheat. Fargo: Extension Service, North Dakota State University, 1995. p.1095.

24. Van Ginkel, M.; Van Der Shaar, W.; Zhuping, Y.; Rajaram, S. Inheritance of resistance to scab in two wheat cultivars from Brazil and China. Plant Disease, St. Paul, v.80, p.863-867, 1996.

25. Verges, V.L. Breeding for Fusarium Head Blight resistance in soft red winter wheat. 2004. 188f. Dissertação (Mestrado) - College of Agriculture, University of Kentucky, Lexington/Kentucky. 